\title{
Micobiota parasitária de escleródios de Sclerotinia sclerotiorum isolada de solos da fronteira oeste do Rio Grande do Sul
}

\section{Parasitic mycoflora of sclerotia of Sclerotinia sclerotiorum isolated from soils of the western frontier of the state of Rio Grande do Sul, Brazil}

\author{
Luciana Zago Ethur ${ }^{1 *}$, Andrio Spiller Copatti ${ }^{1}$, Glauber Monçon Fipke ${ }^{2}$, \\ Caroline Carvalho Aguirre Calvano ${ }^{1}$, Juliano de Bastos Pazini ${ }^{1}$
}

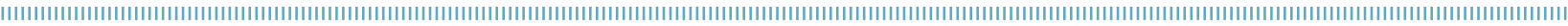

RESUMO: O objetivo do presente trabalho foi identificar a diversidade da micobiota parasitária e o tempo decorrido até o início do parasitismo de escleródios de Sclerotinia sclerotiorum em solos da fronteira oeste do Rio Grande do Sul (RS). Foram coletados solos agrícolas e não agrícolas de cinco localidades na fronteira oeste do Rio Grande do Sul. O isolamento dos fungos foi realizado por meio do teste de iscas, sendo que as iscas foram os escleródios do fitopatógeno, os quais permaneceram enterrados no solo durante 15, 30 e 60 dias. Os fungos foram identificados em nível de gênero. Os gêneros fúngicos encontrados parasitando escleródios foram: Trichoderma, Penicillium, Aspergillus, Fusarium, Pythium (Cromista), Clonostachys rosea (Gliocladium), Chaetomium, Curvularia, Phytophthora (Cromista), Rhizopus, Lichtheimia (Absidia), Mucor, Acremonium, Periconia e Isaria. Observou-se que os escleródios foram parasitados pelos fungos até 15 dias depois de serem enterrados, e deste período em diante apenas a frequência de ocorrência dos fungos mudou. Concluiu-se que os gêneros fúngicos Isaria, Periconia, Acremonium, Lichtheimia (Absidia), Phytophthora, Curvularia e Chaetomium são encontrados em solos agrícolas e não agrícolas na fronteira oeste do RS, e não foram citados anteriormente em outros trabalhos. Existe diversidade de fungos parasitários de escleródios de $S$. sclerotiorum nos solos da fronteira oeste do RS, os quais podem ser utilizados em experimentos para compor um programa de controle biológico desse fitopatógeno. Os escleródios são parasitados pelos fungos durante até 15 dias, após os mesmos serem enterrados no solo.

PALAVRAS-CHAVE: estrutura de resistência; mofo branco; controle biológico.

\begin{abstract}
The aim of this study was to identify the diversity of the parasitic mycoflora and to identify the necessary time until the beginning of the parasitism of sclerotia of Sclerotinia sclerotiorum in soils of the western frontier of the state of Rio Grande do Sul (RS), Brazil. Agricultural and non agricultural soils of five locations in the western frontier of Rio Grande do Sul were collected. The fungi isolation was performed by testing baits, and baits were the sclerotia of the phytopathogen, which remained buried in the soil for 15,30 and 60 days. The fungi were identified at the genus level. The following fungal genera were found parasitizing sclerotia: Trichoderma, Penicillium, Aspergillus, Fusarium, Pythium (Cromista) Clonostachys rosea (Gliocladium), Chaetomium, Curvularia, Phytophthora (Cromista), Rhizopus, Lichtheimia (Absidia), Mucor, Acremonium, Periconia and Isaria. It was observed that the sclerotia were parasitized by fungi until 15 days after they had been buried. And after this period, only the frequency of occurrence of fungi has changed. It was concluded that the fungal genera Isaria, Periconia, Acremonium, Lichtheimia (Absidia), Phytophthora, Curvularia and Chaetomium are found both in agricultural and non-agricultural soils on the western frontier of RS, but they were not previously cited in other works. There is diversity of parasitic fungi of sclerotia of $S$. sclerotiorum in the soils of the western frontier of the RS, which can be used in experiments to compose biological control programs for this pathogen. The sclerotia are parasitized by fungi until 15 days after being buried underground.
\end{abstract}

KEYWORDS: structure strength; white mold; biocontrol.

\footnotetext{
'Universidade Federal do Pampa (UNIPAMPA) - Itaqui (RS), Brasil.

${ }^{2}$ Universidade Federal de Santa Maria (UFSM) - Santa Maria (RS), Brasil.

*Autor correspondente: luethur@gmail.com

Recebido em: 21/08/2012. Aceito em: 26/10/2013.
} 


\section{INTRODUÇÃO}

O Sclerotinia sclerotiorum pertence a um grupo de fungos de solo fitopatogênicos que causa tombamento de pré e pós-emergência, além de podridão no colo ou na parte aérea das plantas. Esse patógeno, conhecido como causador do mofo branco, pode gerar doenças em diferentes espécies vegetais, como plantas ornamentais, hortícolas, culturas comerciais, frutíferas e florestais (BEDENDO, 1995).

A forma de sobrevivência do fungo $S$. sclerotiorum ocorre, principalmente, por meio de estruturas de resistência denominadas escleródios, que permitem que o fitopatógeno sobreviva durante longos períodos no solo na ausência da planta hospedeira (Zамвolim et al., 1999). Os escleródios são agregados de massa de hifas de consistência firme, devido ao envoltório melanizado que se forma na periferia desta estrutura (Morton, 1998; Ferraz et al., 2003). Essas estruturas de resistência armazenam lipídios, carboidratos e proteínas até que as condiçôes do solo estejam suficientemente favoráveis para que haja a germinação carpogênica ou micelogênica (Krugner; Bacchi, 1995; Morton, 1998).

Os escleródios podem se tornar inviáveis de acordo com as condições ambientais, como a alta umidade, que reduz sua longevidade de vários meses para algumas semanas (Amorim, 1995; Morton, 1998; Bueno et al., 2007), e pela ação de parasitas, que podem ser: bactérias (Duncan et al., 2005; Zeng et al., 2012), nematoides (FerraZ et al., 2011), actinomicetos (ZeNG et al., 2012) e fungos (ONDREj et al., 2010; Zeng et al., 2012). Os fungos que constam como parasitas de escleródios de $S$. sclerotiorum são: Coniothyrium minitans Campbell (Huang; Erickson, 2008; Whipps et al., 2008; Zeng et al., 2012), espécies de Gliocladium (Philuips, 2008; Ferraz et al., 2011), Aspergillus spp. (Ferraz et al., 2002; Görgen et al., 2008), Penicillium spp. (Ferraz et al., 2002; Görgen et al., 2008); Mucor sp. (Merriman, 1976); Verticillium spp. (Ferraz et al., 2002), Trichoderma spp. (Ethur et al., 2005; Ferraz et al., 2002; Görgen et al., 2008; ONDREJ, 2010; ZENG et al., 2012), Ulocladium atrum (Figueirềo et al., 2010), Fusarium spp. (Merriman, 1976; Ferraz et al., 2002; Görgen et al., 2008; Ferraz et al., 2011), Rhizoctonia sp. (Ferraz et al., 2011); Cladosporium spp. (Ferraz et al., 2011), Rhizopus spp. (Görgen et al., 2008), Epicoccum purpurascens (Huang; ErICKson, 2008), Talaromyces flavus (HuAng; ERICKson, 2008), Trichothecium roseum (HuANG; ERICKson, 2008) e Sporidesmium sclerotivorum (Del Rio et al., 2002). A descoberta de parasitas das estruturas de resistência desse fitopatógeno é importante para conhecer sua ecologia e buscar medidas para o seu manejo.

De acordo com o exposto, o objetivo do trabalho foi identificar a diversidade da micobiota parasitária e o tempo decorrido até o início do parasitismo de escleródios de $S$. sclerotiorum em solos da fronteira oeste do RS.

\section{MATERIAL E MÉTODOS}

\section{Coleta do solo}

Foram realizadas coletas de solo na regiâo da fronteira oeste do Rio Grande do Sul, nas localidades de: Itaqui, Uruguaiana, São Borja, Maçambará e Alegrete. Em cada ponto de coleta de solo foram tomadas as coordenadas geográficas e a altitude do local, com o auxílio de um Global Position System (GPS) (Quadro 1). Os $5 \mathrm{~kg}$ de solo foram coletados na profundidade de $15 \mathrm{~cm}$ em cinco subamostras na área, em lavouras de grandes culturas, como arroz e soja, e em locais não agrícolas (locais com vegetaçấo nativa), ou seja, dois pontos de coleta por município. Os solos coletados foram guarnecidos em sacos plásticos e transportados até o laboratório de Fitopatologia e Microbiologia do Solo, do Campus Itaqui/UNIPAMPA. Os solos foram coletados em intervalos de três meses, ou seja, os solos agriculturável e não agriculturável de cada município foram coletados para que fossem realizados todos os procedimentos de laboratório, inclusive análise química e física (Tabela 1), para somente depois serem realizadas as coletas de outra localidade.

\section{Isolamento de fungos parasitas de escleródios de S. sclerotiorum}

Para o isolamento dos fungos parasitas dos escleródios utilizou-se o teste de iscas (Ghini; Kimati, 1989; Ethur, 2005). Escleródios de $S$. sclerotiorum produzidos em meio BDA (batata, dextrose e ágar) foram dispostos da seguinte maneira: dez em cada trouxa feita com gaze hidrófila (13 fios por $\mathrm{cm}^{2}$; $7,5 \times 7,5 \mathrm{~cm}$, com quatro dobras), fechada com barbante. Três trouxas contendo os escleródios foram enterradas a $8 \mathrm{~cm}$ de profundidade, em $1 \mathrm{~kg}$ de solo colocado em béquer com capacidade para $2 \mathrm{~L}$. O solo foi umedecido com $5 \mathrm{~mL}$ de água destilada e esterilizada e os béqueres foram fechados com papel alumínio e papel filme. Os béqueres foram mantidos em temperatura ambiente (com variação de 12 a $28^{\circ} \mathrm{C}$ ), sem incidência direta da luz solar.

Foram realizadas três avaliaçôes: 15, 30 e 60 dias após a instalação do experimento, que constou da retirada de uma trouxa de gaze de cada béquer em cada uma das três épocas. Os dez escleródios foram retirados da trouxa e imersos, por cerca de 1 minuto, em álcool (70\%), 1 minuto em hipoclorito de sódio $(0,5 \%)$, três vezes imersos por 1 minuto em água destilada e esterilizada e, posteriormente, deixados para secar por cerca de 10 minutos sobre papel-filtro esterilizado em câmara de fluxo laminar. Cada escleródio foi colocado sobre meio de cultura BDA, em placas de Petri com diâmetro de $9 \mathrm{~cm}$. As placas foram mantidas em câmara climatizada, à temperatura de $22^{\circ} \mathrm{C}$, com fotoperíodo de 12 horas. 
Os fungos encontrados nos escleródios foram identificados diretamente em meio de cultura em torno do escleródio, ou foram repicados para placas de Petri com meio BDA e deixados em câmara climatizada à temperatura de $22^{\circ} \mathrm{C}$, com fotoperíodo de 12 horas. A identificaçáo dos fungos ocorreu em nível de gênero, e foi realizada por meio da observação por microscópios estereoscópico e ótico e pela comparação das estruturas fúngicas vegetativas e reprodutivas, nos parâmetros estabelecidos pela taxonomia convencional, com descriçóes encontradas na literatura especializada (Bisset, 1991; Barnett; Hunter, 1999; Baptista et al., 2004; WatANABe, 2010).

O delineamento experimental foi inteiramente casualizado, em esquema fatorial [ 5 solos de diferentes localidades) x (solo agrícola e não agrícola) x (avaliação em 15, 30 e 60 dias)], com 4 repetições constituídas por 10 escleródios cada.

\section{Análise estatística}

Os resultados dos experimentos foram submetidos à análise de variância pelo teste $\mathrm{F}$ e ao teste de Scott-Knott para a comparação de médias. Utilizou-se a transformação dos dados para arco seno da raiz quadrada de $y / 100$, nas variáveis apresentadas em percentagem. As análises foram realizadas com o auxílio do programa estatístico ASSISTAT.

\section{RESULTADOS E DISCUSSÕES}

Foi encontrada a diversidade de 15 gêneros fúngicos parasitando escleródios de $S$. sclerotiorum nos 11 solos coletados na fronteira oeste do RS (Tabela 2). Esse dado é de extrema importância quando procura-se estudar a ecologia e coletar informaçôes para organizar um programa de controle biológico do patógeno, uma vez que aproximadamente $90 \%$ do ciclo de vida do S. sclerotiorum ocorre na forma de escleródios no solo (Adams; Ayers, 1979). Portanto, os gêneros fúngicos encontrados, mesmo considerando a especificidade de cada isolado e das espécies que nâo foram objetivo de estudo nesse trabalho, podem ser considerados para estudos e pesquisas como potenciais agentes de controle biológico. Segundo Adams; Ayers (1979), os micro-organismos que podem destruir naturalmente os escleródios no solo têm potencial como agentes de controle biológico.

$\mathrm{O}$ solo que apresentou maior número de gêneros fúngicos foi o não agrícola de Alegrete $(53 \%$ dos gêneros encontrados), e os que apresentaram menor número foram os não agrícolas de Itaqui e Maçambará (ambos com 20\% dos gêneros encontrados).

Pode-se observar que o gênero Trichoderma foi encontrado com alta frequência de isolados nos solos coletados (Tabela 1), apresentando $91 \%$ de ocorrência, seguido por

Tabela 1. Localização, local de coleta, coordenadas e composição química e física dos solos coletados na fronteira oeste do Rio Grande do Sul.

\begin{tabular}{|c|c|c|c|c|c|c|c|c|c|}
\hline \multirow{3}{*}{$\begin{array}{l}\text { Localidade - } \\
\text { local de coleta }\end{array}$} & \multirow{3}{*}{$\begin{array}{c}\text { Coordenadas } \\
\text { Latitude (S) } \\
\text { Longitude (W) }\end{array}$} & \multicolumn{8}{|c|}{ Composição química e física } \\
\hline & & $\mathrm{Ph}$ & $\mathbf{P}$ & K & $\mathrm{Ca}$ & $\mathrm{Mg}$ & $\mathrm{H}+\mathrm{Al}$ & M.O. & Argila \\
\hline & & & \multicolumn{2}{|c|}{$\mathrm{mg} \mathrm{dm}{ }^{-3}$} & \multicolumn{3}{|c|}{$\mathrm{cmol}_{\mathrm{c}} \mathrm{dm}^{-3}$} & $\%$ & $\mathbf{g ~ k g}^{-1}$ \\
\hline $\begin{array}{l}\text { Itaqui - } \\
\text { agrícola }\end{array}$ & $\begin{array}{l}29^{\circ} 09^{\prime} 52,4 " \mathrm{~S} \\
56^{\circ} 29^{\prime} 25,2 " \mathrm{~W}\end{array}$ & 5,9 & 20,8 & 15 & 7,6 & 2,8 & 3,1 & 2,3 & 18 \\
\hline $\begin{array}{l}\text { Itaqui - } \\
\text { não agrícola }\end{array}$ & $\begin{array}{l}29^{\circ} 06^{\prime} 37,7 ” \\
56^{\circ} 31^{\prime} 50,7^{\prime \prime}\end{array}$ & 4,9 & 13,5 & 112 & 21,0 & 5,8 & 5,5 & 3,6 & 27 \\
\hline $\begin{array}{l}\text { Maçambará - } \\
\text { agrícola }\end{array}$ & $\begin{array}{l}29^{\circ} 9^{\prime} 27,32^{\prime \prime} \\
56^{\circ} 8^{\prime} 27,37^{\prime \prime}\end{array}$ & 5,1 & 3,7 & 28 & 2,5 & 0,7 & 3,5 & 1,7 & 17 \\
\hline $\begin{array}{l}\text { Maçambará - } \\
\text { não agrícola }\end{array}$ & $\begin{array}{l}29 \circ 9 ’ 37,49 ” \\
569^{\prime} 57,95^{\prime \prime}\end{array}$ & 4,7 & 4,5 & 32 & 1,5 & 0,4 & 3,9 & 2,1 & 16 \\
\hline $\begin{array}{l}\text { São Borja - } \\
\text { agrícola }\end{array}$ & $\begin{array}{l}29 \circ 37^{\prime} 12,4 " \\
55^{\circ} 30^{\prime} 09,99 "\end{array}$ & 5,4 & 50,2 & 124 & 18,5 & 6,7 & 3,1 & 2,7 & 29 \\
\hline $\begin{array}{l}\text { São Borja - } \\
\text { não agrícola }\end{array}$ & $\begin{array}{l}29^{\circ} 37^{\prime} 12,31^{\prime \prime} \\
55^{\circ} 30^{\prime} 33,79 "\end{array}$ & 4,3 & 12,6 & 152 & 5,9 & 1,6 & 10,9 & 1,4 & 30 \\
\hline $\begin{array}{l}\text { Uruguaiana - } \\
\text { agrícola }\end{array}$ & $\begin{array}{l}29^{\circ} 40^{\prime} 26^{\prime \prime} \\
59^{\circ} 54^{\prime} 09^{\prime \prime}\end{array}$ & 5,6 & 17,1 & 84 & 20,6 & 6,9 & 3,9 & 2,1 & 27 \\
\hline $\begin{array}{l}\text { Uruguaiana - } \\
\text { não agrícola }\end{array}$ & $\begin{array}{l}29 \circ 40 ’ 27^{\prime \prime} \\
59 \circ 54^{\prime} 11^{\prime \prime}\end{array}$ & 5,7 & 30,1 & 156 & 20,9 & 6,35 & 2,5 & 2,4 & 62 \\
\hline $\begin{array}{l}\text { Alegrete - } \\
\text { agrícola }\end{array}$ & $\begin{array}{l}29^{\circ} 45^{\prime} 40,5^{\prime \prime} \\
55^{\circ} 51^{\prime} 15,3^{\prime \prime}\end{array}$ & 5,8 & 3,7 & 136 & 16,0 & 7,1 & 2,8 & 1,9 & 20 \\
\hline $\begin{array}{l}\text { Alegrete - } \\
\text { não agrícola }\end{array}$ & $\begin{array}{l}29^{\circ} 45^{\prime} 51,6^{\prime \prime} \\
55^{\circ} 51^{\prime} 00,8^{\prime \prime}\end{array}$ & 6,3 & 6,8 & 76 & 23,4 & 9,2 & 2,0 & 2,8 & 21 \\
\hline $\begin{array}{l}\text { Alegrete - } \\
\text { deserto São João }\end{array}$ & $\begin{array}{l}29^{\circ} 42^{\prime} 10,3 " \\
55^{\circ} 25^{\prime} 53,3^{\prime \prime}\end{array}$ & 4,9 & 3,7 & 12 & 0,1 & 0,2 & 1,7 & 0,2 & 9 \\
\hline
\end{tabular}


Fusarium, Penicillium, Aspergillus e Pythium (Cromista) nas proporçôes de 82, 73, 45 e 45\% dos solos, respectivamente.

Dentre os trabalhos que identificam fungos parasitários de escleródios de S. sclerotiorum, podem-se destacar Ferraz et al. (2002), que encontraram os fungos Penicillium spp., Fusarium spp., Trichoderma spp., Verticillium spp. e Gliocladium spp.; Madsen; Neergaard (1999), que observaram Pythium oligandrum como parasita e como agente de controle biológico do patógeno; Merriman (1976), que isolou Trichoderma, Fusarium e Mucor em experimento com fumigaçáo do solo; e Melo et al. (2006), que constataram que a linhagem de Aspergillus terreus esporulou profusamente sobre os escleródios, rompendo essas estruturas, penetrando e se estabelecendo em seu tecido medular.

Trichoderma spp. foi isolado em maior quantidade de escleródios, na proporção de 35 a $99 \%$ a mais do que os outros gêneros fúngicos (Tabela 2). Esse gênero fúngico foi encontrado parasitando escleródios de S. sclerotiorum por vários autores em diferentes trabalhos relacionados ao controle biológico do patógeno (Merriman, 1976; Adams;

Tabela 2. Presença e média geral de frequência de ocorrência dos fungos (\%) parasitários de escleródios de Sclerotinia sclerotiorum em solos agrícolas e não agrícolas de cinco localidades na fronteira oeste do Rio Grande do Sul.

\begin{tabular}{|c|c|c|c|c|c|c|c|c|c|c|c|c|}
\hline \multirow{3}{*}{ Gêneros fúngicos } & \multicolumn{11}{|c|}{ Solos } & \multirow{3}{*}{ MGFOF* (\%) } \\
\hline & \multicolumn{2}{|c|}{ Itaqui } & \multicolumn{2}{|c|}{ Maçambará } & \multicolumn{2}{|c|}{ Uruguaiana } & \multicolumn{2}{|c|}{ São Borja } & \multicolumn{3}{|c|}{ Alegrete } & \\
\hline & A & NA & A & NA & A & NA & A & NA & A & NA & D & \\
\hline Trichoderma & + & + & + & + & + & + & + & + & + & + & - & $41,1 a^{* *}$ \\
\hline Penicillium & + & - & - & - & + & + & + & + & + & + & + & $17,5 \mathrm{c}$ \\
\hline Aspergillus & + & - & - & - & + & + & + & - & - & + & - & $4,8 d$ \\
\hline Fusarium & + & + & + & - & + & + & - & + & + & + & + & $26,7 b$ \\
\hline Pythium (Cromista) & + & - & + & + & - & - & + & + & - & - & - & $12,9 \mathrm{c}$ \\
\hline Clonostachys rosea (Gliocladium) & - & - & + & + & - & - & - & - & - & + & - & $14,9 \mathrm{c}$ \\
\hline Chaetomium & - & - & - & - & - & + & - & - & - & + & + & $0,4 \mathrm{~d}$ \\
\hline Curvularia & - & - & - & - & - & - & - & + & - & + & + & $3,1 \mathrm{~d}$ \\
\hline Phytophthora (Cromista) & - & - & - & - & + & - & - & - & - & - & - & $0,8 \mathrm{~d}$ \\
\hline Rhizopus & - & - & - & - & - & - & - & - & + & + & - & $0,4 \mathrm{~d}$ \\
\hline Lichtheimia (Absidia) & - & - & + & - & - & - & - & - & - & - & - & $0,4 \mathrm{~d}$ \\
\hline Mucor & - & + & - & - & - & - & - & - & - & - & - & $3,3 \mathrm{~d}$ \\
\hline Acremonium & - & - & - & - & - & - & - & + & - & - & - & $1,0 \mathrm{~d}$ \\
\hline Periconia & - & - & - & - & - & - & - & + & - & - & - & $0,4 \mathrm{~d}$ \\
\hline Isaria & - & - & - & - & - & - & - & - & + & - & - & $0,4 d$ \\
\hline
\end{tabular}

A: Agrícola; NA: Não Agrícola; D: Deserto São João; + : presente, - : ausente.

*MGFOF: Média Geral de Frequência de Ocorrência dos Fungos. Média da percentagem de ocorrência dos fungos nas três avaliações (15, 30 e 60 dias) nos solos agrícolas e não agrícolas e nas cinco localidades. Os fungos encontrados no solo do Deserto São João não foram utilizados na análise estatística. CV: 95,8\%.

**Médias seguidas de letras iguais não diferem entre si pelo teste de Scott-Knott a $5 \%$ de probabilidade.

Tabela 3. Gêneros fúngicos que apresentaram alta frequência de ocorrência de isolados no parasitismo dos escleródios de Sclerotinia sclerotiorum, nos solos agrícolas e não agrícolas em localidades da fronteira oeste do Rio Grande do Sul.

\begin{tabular}{|c|c|c|c|c|c|c|c|}
\hline \multirow{4}{*}{ Localidade* } & \multirow{4}{*}{ Solo } & \multicolumn{6}{|c|}{ Fungos parasitários de escleródios de Sclerotinia sclerotiorum } \\
\hline & & \multicolumn{3}{|c|}{ Fusarium spp. } & \multicolumn{3}{|c|}{ Trichoderma spp. } \\
\hline & & \multicolumn{3}{|c|}{ Avaliações (\%) } & \multicolumn{3}{|c|}{ Avaliações (\%) } \\
\hline & & 15 dias & 30 dias & 60 dias & 15 dias & 30 dias & 60 dias \\
\hline \multirow[t]{2}{*}{1} & A & $13.8 \mathrm{bB} * *$ & $43.3 \mathrm{aA}$ & $16.4 \mathrm{cB}$ & $68.5 \mathrm{aA}$ & $53.6 \mathrm{aA}$ & $35.6 \mathrm{aB}$ \\
\hline & NA & $49.6 \mathrm{aA}$ & $46.4 \mathrm{aA}$ & $36.0 \mathrm{aA}$ & $66.8 \mathrm{aA}$ & $55.0 \mathrm{aA}$ & $52.1 \mathrm{aA}$ \\
\hline \multirow[t]{2}{*}{2} & A & $4.6 \mathrm{cA}$ & $4.6 \mathrm{cA}$ & $0.0 \mathrm{cA}$ & $24.4 \mathrm{bB}$ & $22.4 \mathrm{bB}$ & $56.1 \mathrm{aA}$ \\
\hline & NA & $0.0 \mathrm{cA}$ & $0.0 \mathrm{cA}$ & $0.0 \mathrm{cA}$ & $55.0 \mathrm{aA}$ & $35.6 \mathrm{aA}$ & $44.7 \mathrm{aA}$ \\
\hline \multirow[t]{2}{*}{3} & $A$ & $48.5 \mathrm{aA}$ & $44.9 \mathrm{aA}$ & $40.4 \mathrm{aA}$ & $26.9 \mathrm{bA}$ & $32.1 \mathrm{aA}$ & $38.7 \mathrm{aA}$ \\
\hline & NA & $14.9 \mathrm{bB}$ & $33.7 \mathrm{bA}$ & $35.4 \mathrm{bA}$ & $50.9 \mathrm{aA}$ & $44.7 \mathrm{aA}$ & $51.9 \mathrm{aA}$ \\
\hline \multirow[t]{2}{*}{4} & $A$ & $0.0 \mathrm{cA}$ & $0.0 \mathrm{cA}$ & $0.0 \mathrm{cA}$ & $53.6 \mathrm{aA}$ & $44.5 \mathrm{aA}$ & $41.8 \mathrm{aA}$ \\
\hline & NA & $29.4 \mathrm{bA}$ & $9.2 \mathrm{cB}$ & $11.2 \mathrm{cB}$ & 29.2 bA & $41.6 \mathrm{aA}$ & $29.2 \mathrm{bA}$ \\
\hline \multirow[t]{2}{*}{5} & $A$ & $46.5 \mathrm{aA}$ & $34.5 \mathrm{bB}$ & $25.7 \mathrm{bB}$ & $38.1 \mathrm{bA}$ & 17.8 bB & $46.1 \mathrm{aA}$ \\
\hline & NA & $56.6 \mathrm{aA}$ & $41.8 \mathrm{aA}$ & $26.2 \mathrm{bB}$ & $6.6 \mathrm{cA}$ & $13.7 \mathrm{cA}$ & $9.2 \mathrm{cA}$ \\
\hline CV (\%) & & 49,1 & & & & 29,04 & \\
\hline
\end{tabular}

*1: Itaqui; 2: Maçambará; 3: Uruguaiana; 4: São Borja; 5: Alegrete.

**Médias seguidas de letras minúsculas iguais nas colunas e letras maiúsculas iguais nas linhas não diferem entre si pelo teste de Scott-Knott a $5 \%$ de probabilidade. 
Ayers, 1979; Ferraz et al., 2002; Ethur et al., 2005; ONDREJ et al., 2010).

$\mathrm{O}$ fungo Trichoderma náo foi encontrado no solo com processo de arenização, denominado deserto São Joâo, de Alegrete. O referido solo apresenta composição química e física diferenciada dos demais (Tabela 1), com a menor quantidade de matéria orgânica dentre os 11 solos utilizados no trabalho, o que dificulta a sobrevivência de fungos que vivem saprofiticamente, como Trichoderma.

Dos fungos isolados dos escleródios, cerca de $40 \%$ foram encontrados apenas em um solo (Tabela 2), demonstrando que são específicos para as condiçôes apresentadas no referido solo. Essa informação é importante, principalmente quando procuram-se fungos para serem utilizados em testes como agentes de controle biológico, porque a busca é por micro-organismos que apresentem a capacidade de se desenvolver em diversos solos e condições ambientais. Existe a necessidade de realizar estudos mais específicos sobre a relação das características químicas e físicas do solo (Tabela 1), assim como sobre a sobrevivência dos fungos habitantes desse ambiente. Inclusive, essas análises seriam importantes para a compreensão das inter-relaçóes e da organizaçáo das comunidades e populaçôes microbianas nos agroecossistemas e, especificamente, nos patossistemas.

Os fungos dos gêneros Isaria, Periconia, Acremonium, Lichtheimia (Absidia), Phytophthora, Curvularia e Chaetomium não foram citados na literatura científica como sendo parasitas de escleródios de S. sclerotiorum, portanto, esses fungos podem fazer parte da lista de possíveis antagonistas e serem indicados para testes contra o fitopatógeno. Contudo, existem outros fungos parasitas de escleródios que não foram encontrados nos solos pesquisados, como: Epicoccum purpurascens, Talaromyces flavus e Trichothecium roseum (HuANG; ERICKson, 2008), entre outros.

Houve interação entre os fatores, as diferentes localidades, o solo agrícola e o não agrícola e o tempo de avaliação para a percentagem de isolados dos gêneros fúngicos retirados de escleródios de S. sclerotiorum (Tabela 3).

Aos 15 dias pôde-se encontrar Trichoderma spp. parasitando escleródios, porém, quando se trata de frequência de ocorrência de escleródios parasitados pelo fungo, é possível inferir que aos 15 e 60 dias $90 \%$ estariam infectados, e aos 30 dias, $80 \%$ dessas estruturas conteriam o fungo (Tabela 3). Para o fungo Fusarium spp. também ocorreram variaçóes semelhantes às citadas para Trichoderma, embora o mesmo não tenha ocorrido em todos os solos (Tabela 3).

Portanto, pode-se inferir que os escleródios são parasitados pelos fungos até 15 dias depois de serem enterrados, e que desta época em diante altera-se apenas a frequência de ocorrência dos fungos (Tabela 3). Não foi o objetivo desta pesquisa avaliar a diversidade de fungos parasitários quanto à profundidade dos escleródios no solo e alteraçôes do solo, tais como temperatura. Em trabalho desenvolvido por FERraz et al. (2002) foram encontrados diferentes gêneros fúngicos parasitando escleródios de $S$. sclerotiorum, de acordo com o tempo de solarização do solo e a presença de palhada de milho.

Os solos agrícolas e não agrícolas apresentaram diferenças significativas entre si, entre as localidades e as épocas de avaliação (Tabela 3), porém, as diferenças não são constantes, divergindo para cada fungo encontrado nos escleródios. Assim, não se pode afirmar qual dos solos, agrícola ou não agrícola, apresenta maior diversidade de fungos e incidência do parasitismo nos escleródios.

Observaram-se nematoides parasitando escleródios que estavam em solo agrícola de Alegrete aos 60 dias. Os nematoides foram visualizados em microscópios estereoscópico e ótico e, de acordo com seu aparelho bucal, classificados como micófagos. Nematoides micófagos do gênero Aphelenchoides sp. foram encontrados parasitando escleródios de S. sclerotiorum em solo de cerrado (Ferraz et al., 2011).

\section{CONCLUSÕES}

Os gêneros fúngicos Isaria, Periconia, Acremonium, Lichtheimia (Absidia), Phytophthora, Curvularia e Chaetomium são encontrados em solos agrícolas e não agrícolas na fronteira oeste do RS, e não foram citados anteriormente em outros trabalhos. Existe diversidade de fungos parasitários de escleródios de S. sclerotiorum nos solos da fronteira oeste do RS, que podem ser utilizados em experimentos para compor programas de controle biológico desse fitopatógeno.

Os escleródios são parasitados pelos fungos até 15 dias após serem enterrados no solo. 


\section{REFERÊNCIAS}

ADAMS, P.B.; AYERS, W.A. Ecology of Sclerotinia species. Phytopathology, v.69, n.8, p.896-899, 1979.

AMORIM, L. Sobrevivência do inóculo. In: BERGAMIN FILHO, A.; KIMATI, H.; AMORIM, L. (Ed.) Manual de Fitopatologia. 3. ed. São Paulo: Agronômica Ceres. 1995. p. 126-135.

BAPTISTA, F.R.; PIRES-ZOTTARELLI, C.L.A.; ROCHA, M.; MILANEZ, A.I. The genus Pythium Pringsheim from Brazilian cerrado areas, in the state of São Paulo, Brazil. Revista Brasileira de Botânica, v.27, n.2, p.281-290, 2004.

BARNETT, H.L.; HUNTER, B.B. Ilustrated genera of Imperfect Fungi. Minnesota: American Phytopathology Society. 1999. 218p.

BEDENDO, I.P. Podridão de raiz e colo. In: BERGAMIN FILHO, A.; KIMATI, H.; AMORIN, L. (Ed.) Manual de Fitopatologia. 3. ed. São Paulo: Agronômica Ceres. 1995. p.829-837.

BISSET, J. A revision of the genus Trichoderma III. Section Pachybasium. Canadian Journal of Botany, v.69, p.23732417, 1991.

BUENO, C.J.; AMBRÓSIO, M.M.Q.; SOUZA, N.L. Produção e avaliação da sobrevivência de estruturas de resistência de fungos fitopatogênicos habitantes do solo. Summa Phytopathologica, v.33, n.1, p.47-55, 2007.

DEL RIO, L.E.; MARTINSON, C.A.; YANG, X.B. Biological control of Sclerotinia stem rot of soybean with Sporidesmium sclerotivorum. Plant Disease, v.86, p.999-1004, 2002.

DUNCAN, R.W.; FERNANDO, W.G.D.; RASHID, K.Y. Time and burial depth influencing the viability and bacterial colonization of sclerotia of Sclerotinia sclerotiorum. Soil Biology \& Biochemistry, v.10, p.1-10, 2005.

ETHUR, L.Z.; BLUME, E.; MUNIZ, M.F.B.; SILVA, A.C.F.; STEFANELO, D.R.; ROCHA, E.K. Fungos antagonistas a Sclerotinia sclerotiorum em pepineiro cultivado em estufa. Fitopatologia Brasileira, v.30, n.2, p.127-133, 2005.

FERRAZ, L.C.L.; BERGAMIN FILHO, A.; AMORIM, L.; NASSER, L.C.B. Viabilidade de Sclerotinia sclerotiorum após a solarização do solo na presença de cobertura morta. Fitopatologia Brasileira, v.28, n.1, p.17-26, 2003.

FERRAZ, L.C.L.; NASSER, L.C.B.; CAFÉ-FILHO, A.C. Viabilidade de escleródios de Sclerotinia sclerotiorum e incidência de fungos antagonistas em solo de Cerrado. Summa Phytopathologica, v.37, n.4, p.208-210, 2011.

FIGUEIRÊDO, G.S.; FIGUEIRÊDO, L.C., CAVALCANTI, F.C.N. Biological and Chemical Control of Sclerotinia sclerotiorum using Trichoderma spp. and Ulocladium atrum and Pathogenicity to Bean Plants. Brazilian Archives Biology Technology, v.53, n. 1, p. 1-9, 2010.
GHINI, R.; KIMATI, H. Métodos de iscas para obtenção de isolados de Trichoderma antagônicos a Botrytis cinerea. Jaguariúna: EMBRAPA-CNPDA. 1989. 13p.

GÖRGEN, A.C.; CIVARDI, E.; PERRETO, E.; CARNEIRO, L.C.; SILVEIRA NETO, A.N.; RAGAGNIN, V.; LOBO JUNIOR, M. Controle de Sclerotinia sclerotiorum com o manejo de Brachiaria ruziziensis e aplicação de Trichoderma harzianum. Santo Antônio de Goiás: Embrapa Arroz e Feijão. 2008. 4p. (Embrapa Arroz e Feijão. Circular Técnica, 81).

HUANG, H.C.; ERICKSON, R.S. Factors affecting biological control of Sclerotinia sclerotiorum by fungal antagonists. Journal of Phytopathology, v.156, n. 10, p.628-634, 2008.

KRUGNER, T.L.; BACCHI, L.M.A. Fungos. In: BERGAMIN FILHO, A.; KIMATI, H.; AMORIN, L. Manual de Fitopatologia. 3. ed. São Paulo: Agronômica Ceres. 1995. p.46-95.

MADSEN, A.M.; NEERGAARD, E. Interactions between the mycoparasite Pythium oligandrum and sclerotia of the plant pathogen Sclerotinia sclerotiorum. European Journal of Plant Pathology, v.105, p.761-768, 1999.

MELO, I.S.; FAULL, J.L.; NASCIMENTO, R.S. Antagonism of Aspergillus terreus to Sclerotinia sclerotiorum. Brazilian Journal of Microbiology, v.37, p.417-419, 2006.

MERRIMAN, P.R. Survival of sclerotia of Sclerotinia sclerotiorum in soil. Soil Biology and Biochemistry, v.8, n.5, p.385-389, 1976.

MORTON, J.B. Fungi. In: SYLVIA D.M. (Ed.) Principles and applications of soil microbiology. New Jersey: Prentice Hall. 1998. p.72-93.

PHILLIPS, A.J.L. Factors affecting the parasitic activity of Gliocladium virens on sclerotia of Sclerotinia sclerotiorum and a note on its host range. Journal of Phytopathology, v.116, n.3, p.212-220, 2008.

WATANABE, T. Pictorial Atlas of Soil and Seed Fungi: Morphologies of cultured fungi and key to species. 3rd ed. Boca Raton: Taylor \& Francis Group - CRC Press. 2010.

WHIPPS, J.M.; SREENIVASAPRASAD, S.; MUTHUMEENAKSHI, S.; ROGERS, C.W.; CHALLEN, M.P. Use of Coniothyrium minitans as a biocontrol agent and some molecular aspects of sclerotial mycoparasitism. European Journal Plant Pathology, v.121, p.323-330, 2008.

ZAMBOLIM, L.; COSTA, H.; LOPES, C.A.; VALE, F.X.R. Doenças de hortaliças em cultivo protegido. Informe Agropecuário, v.2O, n.200/202, p.114-125, 1999.

ZENG, W.; WANG, D.; KIRK, W.; HAO, J. Use of Coniothyrium minitans and other microorganisms for reducing Sclerotinia sclerotiorum. Biological Control, v.60, n.2, p.225-232, 2012. 